\title{
Evaluation of Excreta/Secreta of Lucilia sericata Larvae as a New Antibacterial Candidate for Treatment of MRSA Ocular Infection
}

\author{
Hamed Zare 1(1), Khosrow Jadidi ${ }^{2}$, Gholamreza Farnoosh ${ }^{3}$, Maryam Hosseindokht ${ }^{1}$, \\ Marek Kieliszek 4 (D), Hossein Aghamollaei 2,*iD \\ 1 Cellular and Molecular Research Center, Birjand University of Medical Sciences, Birjand, Iran; \\ maryam68128@gmail.com (M.H.); \\ 2 Chemical Injuries Research Center, Systems Biology and Poisonings Institute, Baqiyatallah University of Medical, Tehran, \\ Iran; kh.jadidi@gmail.com (K.J.); \\ 3 Applied Biotechnology Research Centre, Baqiyatallah University of Medical Sciences, Tehran, Iran; \\ rzfarnoosh@yahoo.com (G.F.); \\ 4 Department of Food Biotechnology and Microbiology, Institute of Food Sciences, Warsaw University of Life Sciences- \\ SGGW, Warsaw, Poland; marek_kieliszek@sggw.edu.pl (M.K.); \\ * Correspondence: aghamolaei22@gmail.com (H.A.)
}

Scopus Author ID 55053606400 (H.A.) 55445614900 (H.Z.)

Received: 28.06.2021; Revised: 15.08.2021; Accepted: 18.08.2021; Published: 21.10.2021

\begin{abstract}
Staphylococcus aureus is the most serious cause of bacterial keratitis in most populations. Due to the resistance of this bacteria to methicillin (MRSA), the novel antimicrobial component is required for novel treatments for keratitis. Excretions/secretions (ES) from larvae of Lucilia sericata (maggot) have antibacterial activity against a number of bacteria. Around 500 larvae were washed with $1 \mathrm{~mL}$ of sterile water every hour for ES development. Bactericidal activity of ES was examined by time killing assay. MRSA strain was injected intrastromal into rabbit corneas. The rabbits have been split into three categories, including artificial tear, gentamicin, and maggot ES. Following, the eyes were clinically examined by a slit lamp. This evaluation included the conjunctiva, iris, and cornea. Lastly, the cornea of rabbits was collected for bacterial colony counts. After statistical analysis by ANOVA, it was found that gentamicin and ES, significantly reduced ocular infections in rabbits. Comparisons of corneal opacity scores with Mann-Whitney U-test showed a decreasing trend of therapeutic effects as shown below: gentamicin $>$ ES $>$ control. Gentamicin and ES significantly decrease CFU (number of colony-forming units) compared with the control. The mean bacterial count (log CFU/mL) from corneal culture for ES, gentamicin, and untreated groups were 6.04, 5.0, and 8.9, respectively $(\mathrm{P} \leq 0.05)$. In conclusion, the extraction of maggot larvae is useful in treating keratitis mediated by MRSA.
\end{abstract}

Keywords: Staphylococcus aureus; maggot; antibacterial; ocular infection.

(C) 2021 by the authors. This article is an open-access article distributed under the terms and conditions of the Creative Commons Attribution (CC BY) license (https://creativecommons.org/licenses/by/4.0/).

\section{Introduction}

Bacterial keratitis is one of the most famous eye infections [1,2]. Staphylococcus aureus is the most serious cause of bacterial keratitis in most populations [1-4]. Individuals with contact lenses, persons in old populations, people with diabetes, patients with AIDS, and epithelial trauma caused by means of foreign bodies, are the major groups sensitive to Staphylococcus Keratitis [3,5]. Immunological and pathological examinations have shown bacterial products, and host-associated factors destroy the cornea in keratitis [1,3,5]. S. aureus 
keratitis can cause vision loss, ophthalmia, irreversible corneal scarring, acute inflammation, and corneal perforation $[1,4,6]$.

$\beta$-lactam antibiotics (e.g., cefazolin) with aminoglycoside or fluoroquinolone are currently the selective medicines for keratitis therapy [1-3]. S. aureus infections are especially complicated to treat because of their acquirement of resistance to many antibiotics $[3,7]$. Unfortunately, S. aureus resistance to methicillin (MRSA) developed in 1961 and increases the mortality of infection diseases [7,8]. Accordingly, finding a new antimicrobial drug for keratitis management is crucial $[2,3]$.

Using the sterile maggots of L. sericata (maggot therapy) is a simple, ancient and effective technique for healing necrotic and chronically infected injuries $[8,9,10]$. The success of maggot therapy is due to several reasons. These reasons include eliminating necrotic tissue by enzymatic degradation, destroying and killing of living bacteria to disinfect the wound, producing maggot excreta/secreta (ES) with antibacterial properties, and stimulating tissue formation and wound healing [7,9-11]. ES is heat stable and protease-resistant and has antibacterial activity against a range of bacteria [7,8]. In our investigation, an aqueous extract of maggot larvae (ES) was studied for its in-vivo and in-vitro efficiency in treating the MRSAinduced keratitis disease in rabbits.

\section{Materials and Methods}

\subsection{Production of maggot ES.}

The ES was prepared from sterile second and third instars larvae (L. sericata). About 500 larvae were used for ES production. The maggot larvae were washed every hour with $1 \mathrm{~mL}$ sterile, deionized water. This work was carried out in the darkness for 4 hours. The crude ES was centrifuged $(8000 \times \mathrm{g}, 5 \mathrm{~min})$ to remove large particles and sterilized by $0.20 \mu \mathrm{m}$ methicillin filter $[9,12,13]$. ES sterility was assayed on BHI (brain heart infusion) agar plates.

\subsection{Microorganisms and growth conditions.}

MRSA strain was a gift from the Khatam-al-Anbia hospital (Tehran, Iran). Staphylococcus aureus (ATCC 29213) was achieved from the Iranian Research Organization for Science and Technology as a standard. These bacteria were grown in BHI agar at $37^{\circ} \mathrm{C}$ and kept at $4^{\circ} \mathrm{C}$.

\subsection{In vitro activity of larval ES.}

One colony from the BHI plate was inoculated in $25 \mathrm{~mL} \mathrm{BHI} \mathrm{liquid} \mathrm{nutrient} \mathrm{medium.}$ The incubation was carried out at $37^{\circ} \mathrm{C}$ with shaking $(180 \mathrm{rpm})$ until the cell density of the cultivation reached $5 \times 10^{8}$ cells $/ \mathrm{mL}$. This culture was diluted to reach $10^{2}$ cells per milliliter by BHI broth. Subsequently, $1 \mathrm{~mL}$ of ES was transferred to test tubes containing $1 \mathrm{~mL} \mathrm{BHI}$ and $0.1 \mathrm{~mL}$ bacterial suspension. In the positive growth control tube, $1 \mathrm{~mL} 0.9 \% \mathrm{NaCl}$ was used instead of the ES. Also, the negative control tube was prepared with $2 \mathrm{~mL} 0.9 \% \mathrm{NaCl}$ and $0.1 \mathrm{~mL}$ bacterial culture. Following, the number of surviving bacteria was measured every hour, over 9 hours. $100 \mu \mathrm{L}$ of each sample (test and controls) was cultured onto BHI agar plates, and plates were incubated at $37^{\circ} \mathrm{C}$. Colonies of bacteria were counted overnight. Each trial experiment was repeated three times. 


\subsection{In vivo animal testing.}

White rabbits, all weighing $2.0-3.0 \mathrm{~kg}$ were used. The animals were maintained according to the guidelines of the ARVO (Association for Research in Vision and Ophthalmology). For anesthesia in rabbits, a 1:5 combination of $100 \mathrm{mg} / \mathrm{mL}$ xylazine hydrochloride and $100 \mathrm{mg} / \mathrm{mL}$ ketamine hydrochloride was administered by subcutaneous injection. Proparacaine hydrochloride $0.1 \%$ was spilled into the eye for additional anesthesia (one drop in each eye) [5,14].

\subsection{Determination of ES toxicity.}

At first, the toxic effects of ES on the eye should be investigated. The toxicity effect of ES was assessed by the Draize scoring system on days 0 and 4 for acute toxicity and delayed toxicity, respectively [14]. Draize scale for scoring ocular irritation includes conjunctiva (discharge, redness, and chemosis), iris, and cornea (degree of opacity and area of cornea involved). One drop of ES was instilled into one of the rabbit's eyes every 1 hour for $10 \mathrm{~h}$. Determinations of signs and symptoms related to ES toxicity on the rabbit's eye were evaluated by an ophthalmologist. The MMTS (maximum mean total scores) irritation scores are classified according to table 1 .

Table 1. The MMTS for irritation classification.

\begin{tabular}{l|l} 
Irritation classification & MMTS* \\
\hline Nonirritating & $0.0-0.5$ \\
\hline Practically Nonirritating & $0.6-2.5$ \\
\hline Minimally Irritating & $2.6-15$ \\
\hline Mildly Irritating & $15.1-25$ \\
\hline Moderately Irritating & $25.1-50$ \\
\hline Severely Irritating & $50.1-80$ \\
\hline Extremely Irritating & $80.1-100$ \\
\hline Maximally Irritating & $100.1-110$ \\
\hline $\begin{array}{c}\text { Nonirritating } \\
\text { *Maximum Mean Total Score. }\end{array}$
\end{tabular}

\subsection{Induction of keratitis.}

Keratitis induction was performed as in our previous study [6,15]. Briefly, rabbits were anesthetized, the corneal epithelium was scratched, and $10 \mu \mathrm{L}$ of the bacterial suspension $\left(10^{4} \mathrm{CFU} / \mathrm{mL}\right)$ containing almost $100 \mathrm{CFU}$ of $S$. aureus was injected intrastromal into rabbit's cornea. Also, a sterile corneal fixation ring was used to ensure the same inoculation depth and fix the globes.

\subsection{Treatment and scoring of corneal improvement.}

The rabbits were divided into three groups, with five rabbits in each group. Rabbits were treated immediately with a single topical drop $(25 \mu \mathrm{L})$ every hour, over 10 hours. Treatment on the 2 nd and 3rd days continued with a single topical drop ( $25 \mu \mathrm{L})$ applied every 4 hours. Group 1 was treated with ES, group 2 was treated with gentamicin $(10 \mathrm{mg} / \mathrm{mL})$, and group 3, which is considered as the control group, was untreated. The eyes were evaluated after treatment and graded by a split lamp. The scoring method previously described by Beasel et al. and Aghamollaei et al. $[6,16]$ is summarized in table 2. Finally, the total clinical score was calculated for all treatments, and comparison between the groups was performed with KruskalWallis (K-W) multiple comparisons. 
Table 2. Scoring of corneal improvement.

\begin{tabular}{l|l} 
& Type/Score \\
\hline Eye macroscopically identical to the state of the eyes previous to the bacterial injection & Grade 0 \\
\hline Faint opacity in the injected area & Grade 1 \\
\hline Dense opacity in the injected area & Grade 2 \\
\hline Dense opacity covering the entire anterior segment & Grade 3 \\
\hline Perforation of the cornea & Grade 4
\end{tabular}

\subsection{Bacterial quantification.}

After the last treatment, corneal samples (test and control) were prepared for bacterial quantification. Briefly, the corneas were removed aseptically and homogenized with a tissue homogenizer in $1 \mathrm{~mL}$ of sterile buffered saline (8-10 strokes for 10 seconds and repeated 3 times) [17,18]. After vortexing, $100 \mu \mathrm{L}$ of the homogenate was serially diluted in buffered saline and cultured on BHI agar plates. Incubating culture plates was done at $37^{\circ} \mathrm{C}$, and the number of CFU counted after $24 \mathrm{~h}$. The experiments were performed in duplicate.

\subsection{Statistical analysis.}

Nonparametric one-way analysis of variance (K-W test) and Wilcoxon's test were used for the analysis of the corneal improvement data. Student's $t$-tests and ANOVA (One-way analysis of variance) were used to analyze the bacterial count data. $P$ values $\leq 0.05$ were considered significant.

\section{Results}

\subsection{In vitro antibacterial activity of larval ES.}

One of the goals of our study was to evaluate the sensitivity of Staphylococcus aureus (MRSA) to maggot excreta/secreta (ES). The CFU test was performed, and the effect of ES on the number of viable Staphylococcus aureus was determined. Incubation of S. aureus in BHI with ES revealed that ES reduced the bacterial growth after $3 \mathrm{~h}$ about 3.26 times as compared with the control $(\mathrm{P}<0.01)$ (Figure 1). It should be noted that ES reduces bacterial growth after $1 \mathrm{~h}$ (1.25 times), which was not statistically significant.

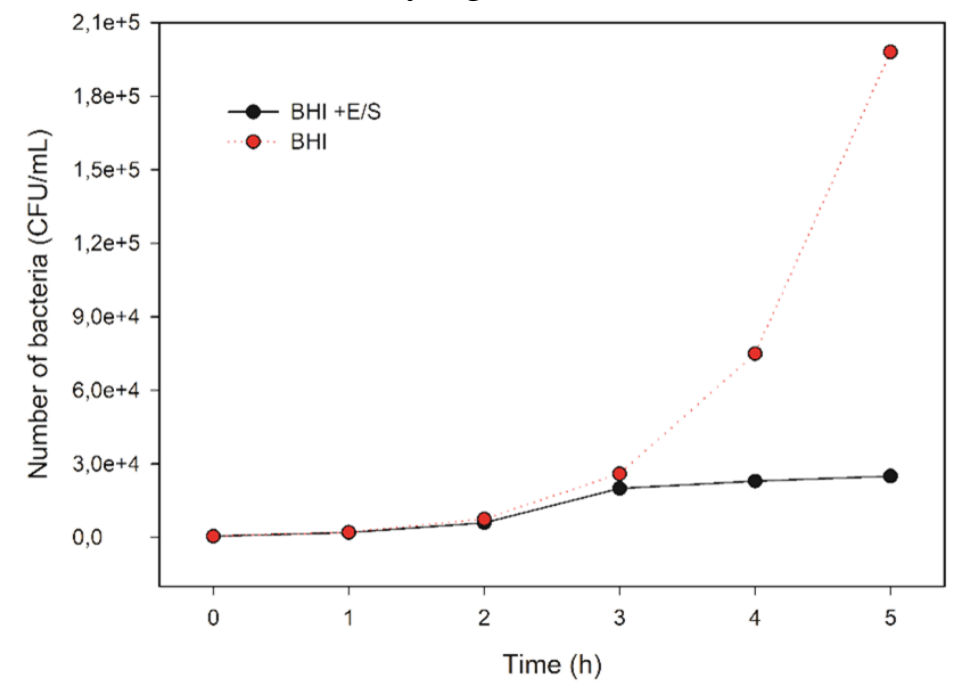

Figure 1. Antibacterial activity of maggot E/S against Staphylococcus aureus; the filtrate ES has stronger inhibitory activity, as compared without maggot E/S. 


\subsection{Determination of ES toxicity.}

Draize testing of normal eyes was performed after adding the ES on day 0 and day 4 . Discharge and redness chemosis is not seen in the conjunctiva. Iris was normal, and corneal epithelial defects were not observed in any of the rabbits. In general, Draize score for conjunctiva, Iris, and the cornea was close to zero. Figure 2 demonstrated the MMTS of rabbit eyes treated with three concentrations of ES and artificial tear as control. As is clear, there was no severe reaction by the rabbits due to the application ES. Moreover, there was no delayed toxicity in treated groups. None of the rabbits had blinked or immediately wiped the eye after pouring the ES into the eyes.

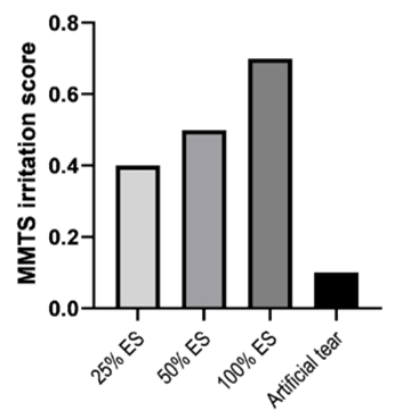

Figure 2. The result of the Draize testing demonstrating the maximum mean total scores (MMTS) of rabbit eyes treated with three concentrations of ES and artificial tear. 1:25\% ES.2: 50\% ES.3: 100\% ES. 4: Control group. The MMTS irritation scores are classified as follows: 0.0-0.5 nonirritating; 0.6-2.5 practically nonirritating.

\subsection{The effect of ES on the treatment of infected corneas.}

To ensure the efficacy of ES extract on ocular infections, the eyes were graded using a slit lamp. Analysis of variance was done after obtaining the amount of total clinical score for all samples. The median corneal opacity scores of the two treatment groups and control group on the $4^{\text {th }}$ (end of treatment) are given in Figure 3. According to variance analysis, both treatment groups (gentamicin and ES) were significantly different from the control group $(\mathrm{P} \leq 0.05)$. But comparing the two treatment groups did not show any significant difference $(\mathrm{P} \leq 0.66)$ (Figure 3). Intergroup comparisons of corneal opacity scores with Mann-Whitney Utest showed a decreasing trend of therapeutic effects as shown below: gentamicin $>\mathrm{ES}>$ control. Also, after treatment with gentamicin and E/S, the rabbits' eyes were clear without any problems (Figure 4). As shown in Figure 4, the rabbit's eyes in the control group were completely opaque.

\subsection{Microbiological load of the corneal tissue.}

As shown in Figure 5, ES significantly reduced the CFU $\left(6.01 \log _{10} \mathrm{CFU}\right)$ in the treatment group eyes compared with the untreated eyes $\left(8.89 \log _{10} \mathrm{CFU}\right)(P \leq 0.01)$. Also, gentamicin reduced the $\mathrm{CFU}\left(5.05 \log _{10} \mathrm{CFU}\right)$ in the treated eyes compared to the control group, and compared to the ES-treated group; this reduction was remarkable. 


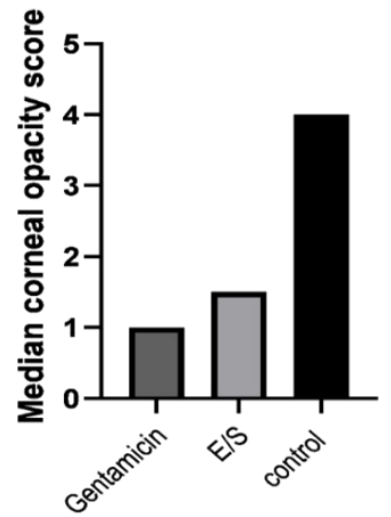

Figure 3. Median opacity scores for all treatment groups reached at the end of the treatment period. The variance analysis showed a significant difference between the two treatment groups (gentamicin and E/S) and the control group $(\mathrm{P} \leq 0.05)$.
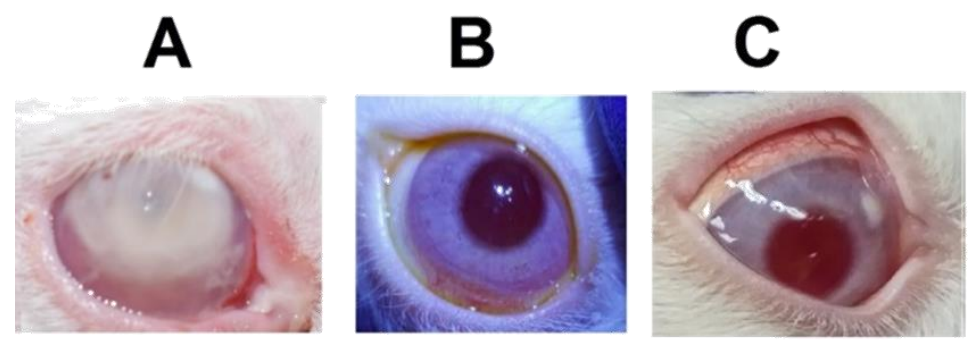

Figure 4. Rabbits' eye 4 days after treatments: A) Control group treated by PBS, B) Group 1 treated by gentamicin, C) Group 3 treated by ES.

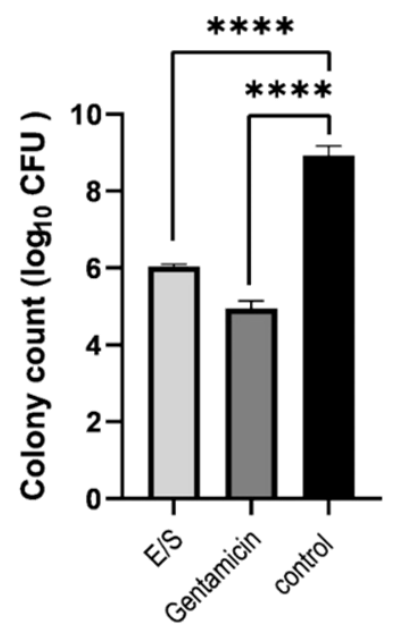

Figure 5. Colony count of bacteria in infected rabbits' cornea after treatment with ES, Gentamicin, and PBS. Both ES and Gentamicin significantly reduced the CFU compared to the control group.

\section{Discussion}

Maggot therapy is a simple and efficient way to treat infected wounds and is used in many countries [7,19]. Currently, it is documented that maggot larva can produce a combination of substances into a lesion and accelerate its healing $[9,20]$. However, the usage of this method in the treatment of ophthalmic infections is subject to limitations. This investigation confirmed that maggot excreta/secreta (ES) is a relatively useful treatment for experimental keratitis caused by $S$. aureus.

Bexfield and colleagues extracted two antibacterial factors from the native ES of $L$. sericata. One of these factors has been isolated using ultrafiltration techniques (weighing less than $500 \mathrm{Da}$ ); has significant antibacterial activity against MRSA [11]. Also, Szczepanowski 
et al. [9] recommended larval therapy, especially for treating Gram-positive bacteria (e.g. Staphylococcus aureus) infection. In addition, Barnes et al. [12] and Elmorsy et al. [13] determined that ES extract has inhibitory effects on the three marker bacterial species (Escherichia coli, Pseudomonas aeruginosa, and Staphylococcus aureus), separately. S. aureus (MRSA) sensitivity to ES was evaluated in our study, and it showed that ES could reduce bacterial growth after 3 hours.

Given that the ES extract contains large amounts of proteins and peptides, it is not unlikely that the antimicrobial properties of this extract will be due to antibacterial peptides [8]. Therefore, it can be concluded that the loss of antibacterial properties of the ES extract after 3 hours may be due to the inactivation of these peptides. One of the concerns about new drugs is their toxicity effect. Draize testing of normal eyes was performed for the determination of ES toxicity. In this study, there was no severe reaction by the rabbits due to the application of ES.

The decrease in bacterial CFU in corneas treated with ES was shown in situ killing of bacteria. In addition, infected corneas treated with ES were observed over 8 days and found to become free of histopathological changes. However, the effect of gentamycin is better than ES, and it's more powerful in reducing the number of bacteria. According to In-vitro results, it can be concluded that the Maggot ES has a bacteriostatic property against $S$. aureus bacteria. The length of ES therapy must be adequate to allow eye defense mechanisms to eliminate the bacteria [19]. Few articles have been published on antimicrobial compounds in maggot ES. Meanwhile, Kruglikova and Chernysh [20] had identified several classes of antimicrobial peptides by examining the ES. In their results, a compound with a molecular mass of $6 \mathrm{kDa}$ was isolated, which possessed a wide range of antibacterial activity against the gram-positive Staphylococcus aureus. In addition, Huberman and et al. [21] found the low-molecular compounds (130 to $700 \mathrm{Da}$ ) with antibacterial properties. These compounds are capable of inhibiting Micrococcus luteus and Pseudomonas aeruginosa. Also, Bexfield et al. [11] examined the antimicrobial activity of the ES with the molecular mass of less than $500 \mathrm{Da}$, and its <500 Da fraction was bacteriostatic with respect to MRSA. Although various compounds in maggot larva excretions have antibacterial properties, the quality of the maggots and physico-chemical conditions available in vivo environment are mentioned as important factors [9].

\section{Conclusions}

Due to the high prevalence of antibiotic-resistant infections in keratitis, new compounds in the treatment of infectious diseases seem very necessary. Maggot ES contains natural antibacterial compounds and according to the results is able to inhibit the growth of MRSA in ocular infections. Further studies are also needed to find the main antibiotic substance of this antibacterial extract.

\section{Funding}

This research received no external funding

\section{Ethics approval}

The research was conducted in accordance with the Declaration of Helsinki and National Standards. 


\section{Conflicts of Interest}

The authors declare no conflict of interest.

\section{References}

1. Lee, J.W.; Somerville, T.; Kaye, S.B.; Romano, V. Staphylococcus aureus Keratitis: Incidence, Pathophysiology, Risk Factors and Novel Strategies for Treatment. J. Clin. Med. 2021, 10, 758, https://doi.org/10.3390/jcm10040758.

2. Maria Cabrera-Aguas, M.; Khoo, P.; George, C.R.R.; Lahra, M.M.; Watson, S.L. Antimicrobial resistance trends in bacterial keratitis over 5 years in Sydney, Australia. Clin. Experiment. Ophthalmol. 2020, 48, 183191, https://doi.org/10.1111/ceo.13672.

3. Durrani, A.F.; Atta, S.; Bhat, A.K.; Mammen, A.; Dhaliwal, D.; Kowalski, R.P.; Jhanji, V. MethicillinResistant Staphylococcus aureus Keratitis: Initial Treatment, Risk Factors, Clinical Features, and Treatment Outcomes. Am. J. Ophthalmol. 2020, 214, 119-126, https://doi.org/10.1016/j.ajo.2020.03.017.

4. Miller, D.; Cavuoto, K.M.; Alfonso, E.C. Bacterial Keratitis. In Infections of the Cornea and Conjunctiva, 85104, 2021, Springer, Singapore, https://doi.org/10.1007/978-981-15-8811-2_6.

5. Lee, J.W.; Somerville, T.; Kaye, S.B.; Romano, V. Staphylococcus aureus Keratitis: incidence, pathophysiology, risk factors and novel strategies for treatment. J. Clin. Med. 2021, 10, 758, https://doi.org/10.3390/jcm10040758.

6. Aghamollaei, H;. Safabakhsh, H.; Moghaddam, M.M.; Zare, H.; Bakherad, H.; Jadidi, K. Evaluation of a Cationic Antimicrobial Peptide as the New Antibiotic Candidate to Treat Staphylococcus aureus keratitis. Int. J. Pept. Res. Ther. 2021, 27, 755-762, https://doi.org/10.1007/s10989-020-10126-3.

7. Chalmers, S.J.; Wylam, M.E. Methicillin-Resistant Staphylococcus aureus infection and treatment options. In Methicillin-Resistant Staphylococcus aureus (MRSA) Protocols, 229-251, 2020, Humana, New York, https://doi.org/10.1007/978-1-4939-9849-4.

8. Khanal, A.; Sulochan, G.C.; Gaire, A.; Khanal, A.; Estrada, R.; Ghimire, R.; Panthee, S. Methicillin-resistant Staphylococcus aureus in Nepal: A systematic review and meta-analysis. Int. J. Infect. Dis. 2021, 103, 48-55, https://doi.org/10.1016/j.ijid.2020.11.152.

9. Szczepanowski, Z.; Grabarek, B.O.; Boroń, D.; Tukiendorf, A.; Kulik-Parobczy, I.; Miszczyk, L. Microbiological effects in patients with leg ulcers and diabetic foot treated with Lucilia sericata larvae. Int. Wound J. 2021, https://doi.org/10.1111/iwj.13605.

10. Cytrynska, M.; Rahnamaeian, M.; Zdybicka-Barabas, A.; Dobslaff, K.; Zuchner, T.; Sacheau, G.; Innis, C.A.; Vilcinskas, A. Proline-Rich Antimicrobial Peptides in Medicinal Maggots of Lucilia sericata Interact With Bacterial DnaK But Do Not Inhibit Protein Synthesis. Front. Pharmacol. 2020, 11, 532, https://doi.org/10.3389/fphar.2020.00532.

11. Bexfield, A.; Bond, A.; Morgan, C.; Wagstaff, J.; Newton, R.; Ratcliffe, N.; et al. Amino acid derivatives from Lucilia sericata excretions/secretions may contribute to the beneficial effects of maggot therapy via increased angiogenesis. Br. J. Dermatol. 2010, 162, 554-562, https://doi.org/10.1111/j.1365-2133.2009.09530.x.

12. Barnes, K.M.;Dixon, R.A.; Gennard, D.E. The antibacterial potency of the medicinal maggot, Lucilia sericata (Meigen): variation in laboratory evaluation. J. Microbiol. Methods. 2010, 82, 234-237, https://doi.org/10.1016/j.mimet.2010.06.005.

13. Elmorsy, R.H.; Bream, A.S.; Abdel-Samad, M.R.K. Antibacterial Activities of Chrysomya albiceps Maggots' Extracts (Diptera: Calliphoridae). Egypt. Acad. J. Biol. Sci. 2020, 13, 99-104, https://doi.org/10.21608/eajbsa.2020.75905.

14. Ledbetter, E.C.; Marion, J.S.; Morrisey, J.K. Amniotic membrane grafting for traumatic complete spectaculectomy and keratomalacia in a Boelen's python (Simalia boeleni). 2021, 24, 295-300, https://doi.org/10.1111/vop.12869.

15. Kowalski, R.P.; Romanowski, E.G.; Yates, K.A.; Mah, F.S. An independent evaluation of a novel peptide mimetic, brilacidin (PMX30063), for ocular anti-infective. J. Ocul. Pharmacol. Ther. 2016, 32, 23-27, https://doi.org/10.1089/jop.2015.0098.

16. Onlen, Y.; Tamer, C.; Oksuz, H.; Duran, N.; Altug, M.E.; Yakan, S. Comparative trial of different antibacterial combinations with propolis and ciprofloxacin on Pseudomonas keratitis in rabbits. Microbiol. Res. 2007, 162, 62-68, https://doi.org/10.1016/j.micres.2006.07.004. 
17. Tahmasebi, T.; Nosrati, R.; Zare, H.; Saderi, H.; Moradi, R.; Owlia, P. Isolation of indigenous Glutathione producing Saccharomyces cerevisiae strains. Iran. J. Pathol. 2016, 11, 354-362.

18. Moradi, R.; Nosrati, R.; Zare ,H.; Tahmasebi, T.; Saderi, H.; Owlia, P. Screening and characterization of invitro probiotic criteria of Saccharomyces and Kluyveromyces strains. Iran. J. Microbiol. 2018, 10, 123-131.

19. Gomes, C.F.; Gomes, J.H.; Silva, E.F. Bacteriostatic and bactericidal clays: an overview. Environ. Geochem. Health. 2020, 42, 3507-3527, https://doi.org/10.1007/s10653-020-00628-w.

20. Kruglikova, A.; Chernysh, S. Antimicrobial compounds from the excretions of surgical maggots, Lucilia sericata (Meigen) (Diptera, Calliphoridae). Entomol. Rev. 2011, 91, 813-819, https://doi.org/10.1134/S0013873811070013.

21. Huberman, L.; Gollop, N.; Breuer, E.; et al. Antibacterial Substances of Low Molecular Weight Isolated from the Blowfly, Lucilia sericata. Med. Vet. Entomol. 2007, 21, 127-131, https://doi.org/10.1111/j.13652915.2007.00668.x. 